\title{
Confiança Institucional e Opinião Pública entre jovens religiosos na cidade do Rio de Janeiro
}

\author{
Paulo Gracino Junior* \\ Janine Targino** \\ Gabriel Rezende***
}

\section{Resumo}

Este artigo mapeia a influência das instituições religiosas na opinião pública de seus fiéis, especificamente jovens, notadamente no que diz respeito às atitudes diante das demandas por reconhecimento da diversidade religiosa, de gênero e comportamento sexual. Subsidiariamente, tendo como ponto de partida os achados de outras pesquisas, avaliaremos o engajamento político e a influência da "pauta moral" como componente do voto desse segmento. A coleta de material se deu em eventos religiosos de massa ocorridos na cidade do Rio de Janeiro entre os anos de 2013 e 2016, mais especificamente, a Jornada Mundial da Juventude (católica), Marcha para Jesus (evangélica de maioria pentecostal), Caminhada por Liberdades Religiosas (ecumênica), utilizando-se como instrumento de coleta a técnica de survey; em uma segunda etapa, selecionamos alguns grupos de jovens para a realização de Grupos Focais, nos quais as questões mais pertinentes do survey puderam ser aprofundadas. A principal conclusão apresentada neste artigo é que o grupo evangélico, quando comparado aos demais aqui analisados, apresenta um contraste mais pronunciado entre sua opinião pública e os "temas controversos", menor tolerância à diversidade religiosa, maior desconfiança com relação às instituições públicas e maior confiança na instituição religiosa.

\section{Palavras-chave}

Jovens religiosos. Confiança institucional. Instituições religiosas.

\footnotetext{
* Paulo Gracino Junior é professor do Programa de Pós-Graduação em Sociologia Política do Instituto Universitário de Pesquisas do Rio de Janeiro (IUPERJ) da Universidade Cândido Mendes (UCAM). E-mail: paulogracino@iuperj.br.

** Janine Targino é professora do Programa de Pós-Graduação em Sociologia Política do Instituto Universitário de Pesquisas do Rio de Janeiro (IUPERJ) da Universidade Cândido Mendes (UCAM). E-mail: janine.targino.silva@gmail.com.

*** Gabriel Rezende é mestre em Sociologia Política pelo Programa de Pós-Graduação em Sociologia Política do Instituto Universitário de Pesquisas do Rio de Janeiro (IUPERJ) da Universidade Cândido Mendes (UCAM).
} 


\section{Abstract}

This article maps out the influence of religious institutions on the public opinion of their believers, specifically young people, notably regarding the reactions when facing the demands of recognizing religious, gender and sexual behavior diversity. Secondarily, starting from the finds in other researchers, we will analyze the political engagement and the influence of the "moral agenda" as a voting component of this segment. The material was collected in religious mass events that took place in the city of Rio de Janeiro between the years of 2013 and 2016, more specifically, the World Youth Day (Catholic), the March for Jesus (Evangelical - mostly Pentecostal), Walk for Religious Freedom (Ecumenical), using the survey technique as a collection tool. In a second phase, we selected a few groups of young people for the Focus Groups, in which the more pertinent issues in the survey were discussed further. The main conclusion presented in this article is that the evangelical group, when compared to the others analyzed here, shows a stronger contrast between their public opinions and the "controversial themes", less tolerance towards religious diversity, more distrust in the public institutions and more trust in the religious institution.

\section{Keywords}

Religious young people. Institutional trust. Religious institutions.

\section{Introdução}

Este artigo mapeia a influência das instituições religiosas na opinião pública de seus fiéis, especificamente jovens, notadamente no que diz respeito às atitudes diante das demandas por reconhecimento da diversidade religiosa, de gênero e comportamento sexual. Neste sentido, a análise proposta se beneficiará, em grande medida, dos dados da pesquisa As novas configurações da religião no século XXI: um inventário sobre jovens participantes em megaeventos religiosos, cujo foco metodológico foi o levantamento de dados a partir de survey's realizados em três eventos religiosos de massa ocorridos na cidade do Rio de Janeiro entre os anos de 2013 e $2016^{1}$.

\footnotetext{
${ }^{1}$ Como ressaltamos, a coleta dos dados quantitativos teve como lugares privilegiados alguns eventos religiosos que aconteceram na cidade do Rio de Janeiro nos anos de 2013 e 2016, a exemplo da Jornada Mundial da Juventude (católica, julho de 2013), Marcha Para Jesus (evangélica, maio de 2014) e da Caminhada em Defesa da Liberdade Religiosa (2016), tendo como público-alvo jovens entre 15 e 30 anos. No caso da JMJ subdividimos o universo - tendo em vista os dados disponibilizados pela organização da JMJ até o dia 23 de julho de 2013 - entre os brasileiros e os demais agrupamentos mais representativos do ponto de vista do número de inscritos: Brasil (424 questionários, $44 \%$ do universo da amostra), América Latina (291 questionários, 30\% do universo da amostra), Europa (172 questionários, 18\% do universo da
} 
Subsidiariamente, com auxílio de trabalhos qualitativos e da literatura, analisaremos os dados que emergiram dessa pesquisa dentro do contexto do avanço do conservadorismo.

O primeiro desses eventos trata-se da Jornada Mundial da Juventude, a qual foi criada pelo Papa João Paulo II em 1985 e, desde então, tem reunido milhões de jovens católicos de todo o mundo com intervalos que oscilam entre dois e três anos. O segundo evento é a Marcha para Jesus, criada em 1987 e de caráter evangélico interdenominacional, embora prevaleça a maioria pentecostal. Esse evento ocorre anualmente em várias cidades do mundo. Já o último evento é a Caminhada por Liberdades Religiosas, criada como resposta aos violentos ataques impetrados por traficantes convertidos a segmentos pentecostais contra religiosos de matrizes africanas em uma comunidade da Ilha do Governador, Rio de Janeiro. As Caminhadas possuem perfil ecumênico e frequência anual.

O levantamento deu origem a um volume considerável de dados que possibilitam cruzamentos exponenciais de variáveis, que vão da aferição de escolaridade e renda ao que chamamos de "temas controversos" - grau de concordância com aborto ou casamento de pessoas do mesmo sexo passando por índice de confiança nas instituições públicas e afinidade discursiva com as instituições e lideranças religiosas. Devido ao volume e à variedade dos dados, neste artigo limitaremos nossa análise a informações referentes à relação entre confiança nas instituições e sua relação com o posicionamento sobre "temas controversos" e tolerância diante da diversidade religiosa e de gênero.

Dentre a diversidade de filiações religiosas aferidas na amostra, o grupo evangélico é o que apresenta um contraste mais pronunciado entre sua opinião pública e os "temas controversos", menor tolerância à diversidade religiosa, desconfiança com relação às instituições públicas e maior confiança na instituição religiosa. Tal constatação não chega a ser uma

amostra), América do Norte (57 questionários, 6\% do universo da amostra) e Outros (30 questionários, 3\% do universo da amostra). No caso da Marcha para Jesus, evento de fundo evangélico pentecostal, liderada pelo Pastor Silas Malafaia da Assembléia de Deus Vitória em Cristo, que reúne anualmente cerca de 500 mil pessoas nas ruas do Centro do Rio de Janeiro, foram aplicados 292 questionários, em um único dia (31 de maio de 2014), durante os eventos da Marcha. Seguimos o mesmo expediente na Caminhada em Defesa da Liberdade Religiosa, que reúne uma miríade de orientações religiosas que vão desde candomblecistas, umbandistas, hare krishnas, judeus, protestantes, até wiccas e agnósticos. Esse evento ocorre anualmente no bairro de Copacabana, geralmente no mês de setembro, sendo que a coleta dos dados que serão analisados aqui foi feita na $8^{a}$ edição ocorrida no dia 18 de setembro de 2016, na qual foram entrevistadas 501 pessoas. 
surpresa, uma vez que a literatura tem apontado que os estratos religiosos de cariz protestante, em nosso caso os evangélicos de origem pentecostal ou renovada ${ }^{2}$, e no caso dos EUA os evangelicals, guardam maior nível de strictness (IANNACCONE, 1994; STARK; FINKE, 2000, p.197) em relação à cultura vernacular que os cerca (SMITH, 1998, 2003).

No Brasil esse cenário chama a atenção tanto pela forma ativa com que algumas lideranças do campo evangélico têm se posicionado publicamente diante do que chamamos de "demandas por reconhecimento" (TAYLOR, 1994, 2011; HONNETH, 2009) da diversidade de gênero e comportamento sexual, quanto pelas estratégias de que algumas dessas igrejas têm lançado mão para mobilizar discursivamente o mal-estar atual vivido pela sociedade brasileira e organizá-lo tanto em dispositivos normativos quanto em consensos públicos nos termos habermasianos (HABERMAS, 1989, 2003). Neste sentido, é preciso acrescentar que os próprios grupos evangélicos reivindicam sua maior presença no espaço público falando do lugar de minoria religiosa que sempre esteve marginalizada, seja na política, seja na cultura mais ampla, principalmente, diante de uma Igreja Católica ou de uma cultura laica, vistas como hegemônicas na ocupação de cargos públicos ou visibilidade midiática. Importante ressaltar que a reivindicação de grupos evangélicos por liberdade religiosa, tal como o fazem as minorias religiosas, pode ser vista como parte de uma performance que, ao mesmo tempo, insinua um projeto de maioria. Ou seja, é possível dizer que as "minorias" religiosas evangélicas agem com dualidade (GIUMBELLI, 2008, p.96).

Especialmente no caso da política partidária, de acordo com Mariano (2011), ocorria um movimento de autoexclusão dos pentecostais fundamentado no lema "crente não se mete em política". No entanto, esse cenário começa a mudar com a alegação de que era necessário que os pentecostais passassem a defender seus interesses institucionais e seus valores morais contra seus adversários católicos, homossexuais, "macumbeiros" e feministas. Assim, a Assembleia Nacional Constituinte,

\footnotetext{
${ }^{2}$ Utilizaremos aqui o termo evangélico para nos referir tanto aos pentecostais e neopentecostais quanto aos pertencentes a igrejas renovadas, que não se identificam com os grupos descritos, porém guardam traços teológicos, características discursivas e práticas públicas que se assemelham aos grupos pentecostais e neopentecostais. É importante notar que em trabalhos anteriores já havíamos chamado a atenção para essa diluição das fronteiras denominacionais no campo religioso evangélico (MARIZ; GRACINO JUNIOR, 2013).
} 
eleita em 1986, não só simbolizou a redemocratização como também "inaugurou um vigoroso ativismo pentecostal na política partidária nacional" (MARIANO, 2011, p.250).

Antes de prosseguirmos, é importante salientar que, embora nas últimas três décadas o imbricamento entre esfera pública e esfera religiosa tenha se mostrado mais evidente no Brasil, principalmente devido ao crescimento dos grupos evangélicos e sua visibilidade pública, o processo de laicização do país está longe de guardar uma trajetória retilínea. Nesse sentido, o surgimento da "bancada evangélica" com a eleição de 33 parlamentares para o Congresso Nacional Constituinte em 1986 (PIERUCCI, 1989) bem como sua consolidação como uma força política dentro do Congresso nas eleições posteriores não pode ser tomada como um refluxo no processo de laicização da esfera pública brasileira, iniciado pelo processo de separação Estado/Igreja promovido pela Constituição de 1891. A religião - institucional ou não - continuou ocupando lugar de destaque e constituindo tanto a cultura quanto a política brasileira.

No entanto, quando assistimos a embates entre movimentos organizados da sociedade civil e líderes religiosos a respeito do lugar da religião na esfera pública, pensamos que algo possa ter mudado desde que o catolicismo, em sua vertente popular, romanizada ou da libertação ocupava o centro dessas discussões. Mas o que teria mudado com a entrada dos evangélicos e católicos carismáticos na cena pública, qual o escopo dessa mudança?

Para entendermos tal processo, partimos da tese habermasiana em Naturalismo e Religião (HABERMAS, 2007, p.119-120), que servirá como pano de fundo e amálgama das teses mais específicas que defenderemos sobre o fenômeno em solo brasileiro. Segundo Habermas, um Estado liberal, ainda que possa obter sua autolegitimação de maneira autossuficiente, através de recursos cognitivos que não dependam de discursos estranhos à esfera política, necessita manter a aderência de seus "cidadãos do Estado", ou seu status, através de pequenas virtudes do político, ou seja, através de uma sociedade civil que se alimenta de fontes "pré-políticas". Nesse sentido, para o autor, ao contrário dos "cidadãos da sociedade" (Gesellschaftbürger) - que são destinatários do direito - os cidadãos do Estado (Staatsbürger) se autoentendem como coprodutores das leis e, nas palavras de Habermas, "devem assumir seus direitos de comunicação e de participação de modo ativo, não somente no sentido bem-entendido do interesse próprio, mas também devem ser orientados pelo bem comum". (HABERMAS, 2007, p.119). 
Afora os pressupostos normativos dessas premissas, somos conduzidos por elas ao ponto nodal da argumentação, que alinhava, como dissemos, todas as nossas questões subsidiárias e específicas: bem, se a ágora pública necessita de discursos pré-políticos para manter os seus cidadãos do Estado engajados e se esses discursos devem, nas palavras de Habermas, ensejar valores universais e um bem comum, o que aconteceria se os postulados de Sennett $(1999)$ e Taylor $(1994,2011)$ estiverem corretos? E se, ao invés de um espaço público dialógico, como propõe Habermas, estivermos diante de uma arena pública escassa, ou, nas palavras de Sennett (1999, p.28), de um espaço público morto, em que a exacerbação das relações impessoais de mercado leva a uma privatização da sociedade e ao autocentramento na instrumentalização do mundo, de modo que o sujeito não confere nenhuma legitimidade a demandas externas a seus self, como em Taylor, como argumenta Isabel Oliveira (2006)?

No caso brasileiro, após a Constituição de 1988, como apontam vários pesquisadores (SINGER, 2012, 2016; BRAGA, 2012), ainda que se tenha avançado em políticas de inclusão social e cidadania, principalmente após o período de ascensão do Partido dos Trabalhadores ao poder (2003-2016), "viu-se a inclusão de vastos setores no processo violento de valorização do capital, implicando uma integração que, contraditoriamente, não significava necessariamente cidadania" (SINGER, 2016, p.13). Soma-se a esse quadro o embate político/midiático em curso nos últimos 15 anos, fruto de uma disputa pelo poder entre grupos políticos e conglomerados empresariais ligados à mídia, que parece ter erodido ainda mais a já precária cultura política da população brasileira.

Nesse bojo, bandeiras como igualdade racial e de gênero, inclusão social, direitos humanos, passaram a ser identificados como bandeiras estritamente ligadas ao campo da esquerda e logo rechaçadas por diversos setores da sociedade. Paralelamente, e em consequência dessas disputas políticas, líderes religiosos conservadores, portadores de uma moral draconiana no sentido que lhe dá Sennett (2006) - e pregadores de uma ética religiosa individualista e bem afinada ao capitalismo flexível (GRACINO JUNIOR, 2008) no qual "só os mais competentes se estabelecem" ${ }^{3}$, onde “Deus trabalha

\footnotetext{
${ }^{3}$ Mensagem do Bispo Robson Rodovalho, Igreja Sara Nossa Terra. Disponível em: <www.saranossaterra. com.br/categorias.asp?cat=7\&nome=Mensagem\%20do\%20Bispo> Acesso em 14 de dezembro de 2006.
} 
com a lei da recompensa" ${ }^{4}$, foram empoderados e ganharam cada vez mais legitimidade pública, inclusive em meio à população não evangélica.

Diante do quadro traçado, da bibliografia especializada e dos dados da pesquisa supracitada, tende-se a sugerir quatro hipóteses a esse respeito: a primeira é bastante clássica e já enunciada, ou seja, os grupos pentecostais guardam um maior nível de ascese intramundana e acreditam em uma conduta ativa na transformação do mundo. Em nossa hipótese há uma tradução, nos termos que coloca Luhmann (2007), dos processos sociais em discurso teológico. $\mathrm{O}$ discurso religioso é visto como uma resposta normativa para um mundo que aparentemente está caminhando para uma direção diferente e desastrosa (BEYER, 1990).

Tal processo parece ganhar força em reação a uma transformação do espaço público, na medida em que ocorre o enfraquecimento do credo moderno, bem como das instituições produtoras de sentido que sustentavam discursivamente esse "espaço público". Nos dias que correm, partidos, sindicatos e até mesmo Estados têm suas agendas pautadas por interesses privados e de curto prazo, o que leva ao seu enfraquecimento como instituição normativa (no caso específico do Estado) e fomentadora de debates públicos mais amplos. Tal processo abriria espaço na arena pública para a atuação de novos atores que pudessem, com maior eficácia, traduzir esses anseios individuais e de curto prazo para o discurso institucional - em nosso caso as agências religiosas.

O processo de "modernização autoritário" pelo qual se constituíram as instituições brasileiras bem como seu espaço público não fomentou, logicamente, o acolhimento dos anseios de diversos estratos sociais, que, alijados do processo de modernização, com acesso precário às instituições do Estado, depositam nelas um baixo nível de confiança. Assim, tais atores, com pouca participação nas instituições públicas e de representação, são mais propensos a procurar formas alternativas de expressão/ressignificação de seus anseios, vendo nas instituições religiosas possibilidades de mediação entre seus interesses e o espaço público.

Paralelamente a esses fenômenos, temos, principalmente após a Constituição de 1988, o reconhecimento por parte do Estado do fato religioso

\footnotetext{
${ }^{4}$ Pregação do Pastor Silas Malafaia. Uma vida de prosperidade. Programa Vitória em Cristo (02/06/2012). Disponível em: <https://www.youtube.com/watch?v=kDFmctcG2GY>. Acesso em 15 de novembro de 2016.
} 
como constitutivo do espaço público. Nesse sentido, são acolhidas diversas demandas por reconhecimento dos grupos religiosos, passando-se de uma situação de regulação das crenças para um pluralismo igualitário, ou, nos termos de Portier (2011), laicidade de reconhecimento. Assim, acompanhando reflexões anteriores (GRACINO JUNIOR, 2010, 2016; MACHADO; BURITY, 2014), vemos o crescimento da influência pública de grupos religiosos não católicos, em especial evangélicos pentecostais, como constituinte do processo de democratização do país no pós-ditadura militar e consequente pluralização cultural.

\section{Confiança Institucional e Influência Pública da Religião}

Para entendermos tal cenário, acreditamos ser necessária uma breve incursão ao que autores como Luhmann e Giddens entendem como confiança. Comecemos por lembrar que para Luhmann (1996) a confiança é um tipo de redução da complexidade do sistema social, ou seja, na impossibilidade de montarmos planos de ação que levem em conta as infinitas contingências futuras, baseamo-nos em constructos de uma realidade pré-ordenada e pré-selecionada por indivíduos e instituições - no caso de Luhmann, por subsistemas. Para o autor de Sistemas Sociais, a sociedade contemporânea está dividida em subsistemas especializados - econômico, cultural, político, religioso, etc. - que se relacionam com a sociedade como um todo por meio de uma função e com outros subsistemas pelo que denominou desempenho. Assim, a função primordial de um sistema seria traduzir em discurso para o seu interior os aspectos básicos da realidade exterior (ambiente), através de um código central binário que estabelece termos positivos e negativos, a exemplo de "dentro" e "fora" da lei no subsistema jurídico; ou "falso" e "verdadeiro" nas ciências, ou imanência e transcendência para a religião.

Mas o que geraria a confiança nesses "sistemas"? Para Giddens (1991, p.93-96), em proposição nitidamente tributária à de Luhmann, a confiança passa por uma inculcação pedagógica da validade de tais sistemas, "sistemas peritos", que é feita desde os primeiros anos escolares através do que ele chama de "currículo oculto". Com tal termo, Giddens quer dizer, sem questionar o caráter real ou construído dos sistemas em questão, que o processo de educação formal é, antes de tudo, um processo de legitimação do conhecimento científico-racional.

Se formos mais longe, podemos imaginar, como Foucault (1979, p.14), que 
"a verdade está circularmente ligada a sistemas de poder, que a produzem e a apoiam, e a efeitos de poder que ela induz e que a reproduzem", ou seja, a construção da confiança é um ato discricionário de um discurso que se impõe sobre uma realidade infinita - ou complexa, diria Luhmann (2007). Não é sem razão que Habermas compara, em tom de crítica, as propostas de Luhmann e Foucault: "Luhmann transfere para os sistemas que processam o sentido e o operam (...) as mesmas propriedades que Foucault, com auxílio de um conceito histórico-transcendental de poder, atribuíra às formações discursivas" (HABERMAS, 2001, p.492).

Afora o problema da arbitrariedade dos discursos gerados pelo sistema, sua legitimidade reside na capacidade de tradução eficaz das questões sociais para o discurso interno, gerando a confiança no sistema: um litígio entre duas pessoas é traduzido para e resolvido no sistema jurídico; um problema de escassez, traduzido em planilhas econômicas, etc. No entanto, a incapacidade de solucionar tais problemas deixa margem para que os mesmos possam ser alvo de outros subsistemas, o que Luhmann (2009) classifica como desempenho. Além disso, não é difícil imaginar que a incapacidade de um sistema resolver problemas possa colocar em xeque a confiança que se lhe atribui, reduzindo seu poder de atração e causando, por conseguinte, sua decadência.

Neste ponto, chegamos a um nó teórico que parece ser necessário desatar antes de prosseguirmos: o fato de utilizarmos os conceitos da sociologia luhmanniana não quer dizer que coadunamos com o autor em todos os pontos de seu arcabouço teórico. Em especial, distanciamo-nos, principalmente da segunda fase do pensamento de Luhmann e sua "virada autopoiética", ou seja, que estabelece autorreferencialidade e o fechamento operacional dos subsistemas. Ao dar esse passo, Luhmann não concebe mais os indivíduos como sujeitos arbitrários, mas como sujeitos cognoscentes voltados para o conhecimento de si mesmos. Para o autor, em um mundo complexo, funcionalmente diferenciado, o "mundo da vida" perdeu todo o significado, ou, como observa Habermas (2001):

As operações para construir um mundo de um sujeito transcendental - que perdeu seu status de independência em relação ao mundo e foi rebaixado ao nível do sujeito empírico - são reconceitualizadas enquanto operações de um sistema que opera significativamente de maneira auto-referencial e que é capaz de representar internamente seu mundo circundante. A 
produtividade criadora de ficções (...) para qual a diferença entre verdade e ilusão perdeu todo o sentido, é reconceitualizada como sistema que domina a complexidade de seu mundo circundante, utilizando o asseguramento de sentido que intensifica sua própria complexidade (...) [este] triturador incansável de reconceitualização elimina, como resíduo indigesto, todo mundo da vida 'subcomplexo'. (HABERMAS, 2001, p.491-492).

Desta forma, parece-nos que a proposição de outro autor alemão, Claus Offe, sobre o conceito de confiança faz um reparo ao modelo luhmaniano e lhe confere maior poder explicativo e adequação ao caso que ora propomos. Para Offe (1999), a confiança constitui elemento fundamental para o funcionamento das instituições, porque suas regras estruturantes remetem aos conteúdos normativos usados como referência pelos cidadãos na forma como se relacionam com as estruturas da comunidade política da qual fazem parte. Por isso, as instituições não podem ser vistas como neutras, uma vez que funcionam como mecanismos de mediação orientados segundo os valores relativos aos objetivos coletivos que busca concretizar. É importante ressaltar que, embora uma análise superficial do panorama geral das novas democracias indique a existência de uma crise política, o que ocorre de fato é a dificuldade do novo regime em tornar mais densa a ligação entre os cidadãos e as estruturas de poder. Esse fenômeno em si não impede a existência do regime democrático, embora seja um limitador para que este possua plena capacidade de coordenar ações coletivas. Ou seja, se as instituições não podem contar com a confiança dos cidadãos, elas não conseguem atuar como instrumento de mediação entre suas expectativas e os objetivos coletivos visados pelos governos e pelas lideranças políticas. E, para que as instituições consigam arregimentar confiança, é necessário que seus gestores sejam capazes de traduzir aos cidadãos a ideia ou princípio básico que orienta e articula cada instituição específica. Portanto, a anuência dos cidadãos para com as regras de comportamento provenientes da ação dos gestores das instituições está sujeita à capacidade discursiva das instituições (OFFE, 1999).

Dito isto, estamos prontos para avançar em direção à compreensão da manutenção do vigor da religião em um espaço público dotado de demandas plurais de toda sorte. Neste sentido, o que explicaria a manutenção dos índices de confiança nas instituições religiosas, dada a escassez generalizada de confiança nas instituições que marca a sociedade 
contemporânea ${ }^{5}$ ? A resposta parece estar na capacidade de as religiões interagirem com uma realidade social em contínua transformação. As instituições religiosas respondem às demandas da sociedade acoplando (LUHMANN, 2009) e resolvendo problemas gerados em outro subsistema que não o religioso. Quando uma religião traduz para o discurso teológico problemas gerados em outro subsistema, como o econômico, por exemplo, tais problemas não se tornam, de forma alguma, religiosos. Por conseguinte, tais soluções tenderão a assumir as características do subsistema de que são provenientes: soluções econômicas para problemas econômicos e políticas para problemas políticos (Cf. BEYER, 1990). Os pastores da Igreja Universal do Reino de Deus (IURD) ${ }^{6}$, por exemplo, sabem que não é por meio da oração, ou pelo menos só da oração, que se resolverá um problema gerado fora do âmbito religioso, como podemos ver na fala de Edir Macedo:

Em toda a Bíblia, vemos a necessidade da sociedade do homem na realização dos Seus milagres. Trata-se de uma condição determinada pelo Senhor desde a criação. O povo de Deus tem de se conscientizar disso, a fim de não ficar à toa, esperando as promessas divinas caírem do Céu. (MACEDO, 2006) .

Voltemos a Beyer para interpretação da retomada da influência pública da religião. Segundo este, para se ter uma religião publicamente influente, não basta um elevado nível de religiosidade individual, traduzido em ações públicas religiosamente orientadas, ou que os líderes religiosos sejam capazes de rotinizar essa religiosidade em organizações e movimentos institucionalizados, mas, antes, que esses líderes tenham controle sobre um

\footnotetext{
${ }^{5}$ Segundo pesquisa do IBOPE, as instituições religiosas são as que mais inspiram confiança nos brasileiros (76\%), perdendo apenas para a família (90\%) e os bombeiros (88\%), noto que os partidos políticos (31\%), o Congresso Nacional (35\%) e os sindicatos (46\%) são os últimos da lista. Disponível em: <http://www.ibope.com.br/calandraWeb/servlet/CalandraRedirect?t $\mathrm{emp}=5 \&$ proj=PortalIBOPE $\&$ pub $=\mathrm{T} \& \mathrm{db}=\mathrm{caldb} \& \mathrm{comp}=\mathrm{IBOPE}+$ Intelig\%EAncia\&docid $=\mathrm{A} 518$ AE36007849548325767A004C951B >. Acesso em 07 de dezembro de 2010.

${ }^{6}$ Fundada pelo Bispo Edir Macedo na segunda metade da década de 1970, a IURD alcançou notoriedade a partir da década de 1980. Caracterizada pela prática de proselitismo agressivo que não poupava seus opositores, a IURD passou a se apresentar como um espaço sagrado capaz de resolver mazelas que, segundo os preceitos seguidos pela igreja, são provocadas pela ação demoníaca (MENESES, 2017).

${ }^{7}$ Os exemplos do Calvário, Bispo Edir Macedo. Disponível em: www.arcauniversal.com.br/ fogueirasanta/2006-2/vhtml/img/menu1.jpg. Acesso em 12 de dezembro de 2006.
} 
serviço intimamente necessário nos dias de hoje, como fazem, por exemplo, os profissionais de saúde. Continuando em seus argumentos, diz que a globalização altera significativamente a forma como a religião consegue alcançar sua influência pública, uma vez que tal processo mitigaria a possiblidade de representar estranhos como personificação do mal, o que, por consequência, debilitaria os códigos deontológicos, já que o bem seria difícil de se identificar na ausência de um mal iminente, minando mensagens de salvação aos moldes tradicionais. Por outro lado, ainda que seja difícil para a religião readquirir a influência em termos globais, Beyer acredita que os líderes religiosos tradicionais podem aplicar as modalidades religiosas tradicionais para promover uma mobilização política subsocial em resposta à globalização da sociedade (BEYER, 1990, p. 396). É interessante observar que autores como Smith (1998) e antes dele Kelley (1978) se questionavam sobre os motivos do crescimento de igrejas conservadoras: Why Conservative Churches Are Still Growing.

No que tange à forma como a religião alcançará e exercerá sua influência pública, Beyer nos apresenta duas alternativas: a que ele denomina liberal e a conservadora (BEYER, 1990, p. 407). Na primeira delas há a consideração de que existe o mal no mundo, mas ele não pode ser localizado e/ ou personificado de forma clara. O mal, nessa perspectiva, constitui uma limitação em todos nós e presente em todas as estruturas sociais. Assim, o mal não pode ser localizado na pluralidade, incluindo aqui o pluralismo religioso. De fato, sob esse prisma, a intolerância e a imputação particularista é que se tornam a fonte do mal. Assim, os profissionais da religião inclinados à opção liberal assumem uma postura ecumênica e tolerante, além de apontarem possibilidades de iluminação e de salvação em sua própria religião e em outras religiões. Para Beyer, o problema teológico fundamental dessa alternativa é que a mesma apresenta poucas exigências tipicamente religiosas, sendo que a maioria de seus atrativos também podem ser conseguidos através de instituições não religiosas (BEYER, 1990, p. 408). Deus, por exemplo, é representado por essa vertente como sendo um ser benevolente e não vingativo, cuja única exigência é que as pessoas imitem suas atitudes em relação a seus semelhantes. No entanto, essa combinação de pluralismo e inclusão deixa de fora uma parcela ínfima dos indivíduos dos benefícios quase que automáticos da função religiosa (BEYER, 1990, p. 409).

Para o público brasileiro não é difícil encontrar exemplos empíricos do cenário teórico descrito por Beyer, já que a Teologia da Libertação 
e seus desdobramentos entre nós são bastante conhecidos. Trabalhos de pesquisadores como Burdick, (1998 [1993]) e Mariz (1994), mesmo que sob perspectivas teóricas diferentes, mostram as dificuldades encontradas pelas Comunidades Eclesiais de Base na tentativa de mobilização de demandas específicas/cotidianas de agentes. Nesse mesmo turno, vemos como a opção liberal de caráter mais humanista e universal, propalada por alguns líderes religiosos católicos e protestantes, encontra dificuldade de aceitação em alguns estratos sociais, ao passo que opções conservadoras ganham cada vez mais notoriedade pública, inclusive entre a população não religiosa.

Voltando ao que nos diz Beyer, já a alternativa conservadora está longe de ser apenas um retrocesso vinculado às estruturas sociais ultrapassadas, além de ser a única opção que está tornando a religião visível na atualidade. Melhor dizendo, a alternativa conservadora trata-se de um aspecto vital da globalização, e não uma forma de negá-la. No que diz respeito à fé em particular, a opção conservadora promove a confirmação da visão tradicional da transcendência, confirmação esta que, muitas vezes, se concretiza como uma resposta normativa a uma sociedade que pode estar caminhando para uma direção desastrosa (ver também SMITH, 1998, 2003). Diferentemente da opção liberal, a via conservadora atravessa menos problemas com a transcendência, embora possa entrar em conflito com algumas tendências na estrutura social global mais liberais. Ainda, devese acrescentar que a religião conservadora reflete as estruturas modernas na medida em que é capaz de dissolver determinadas disparidades entre a estrutura dos sistemas pessoais e o sistema social (BEYER, 1990, p. 412).

\section{As Igrejas diante da Crise Brasileira}

Se recuarmos no argumento de Beyer, veremos que a ideia de um mal absoluto, universal, que pudesse simbolizar todos os medos sociais - como foi a figura de satanás para demonstrar a importância de Deus e da salvação em certa altura do cristianismo - , foi bastante funcional para reforçar os códigos deontológicos. Os líderes religiosos e políticos, em diversos momentos da história, valeram-se desse expediente ao identificarem a ameaça externa a seu grupo social, ou seus correlatos morais internos a sua própria sociedade com encarnações do mal. Quem não lembra da expressão "Eixo do Mal", adotada pelo presidente dos EUA, George W. Bush, para se referir a governos que ele considerava hostis aos EUA? Ou, para ficarmos em âmbito mais doméstico, das alcunhas nada amigáveis com as quais 
o pastor Silas Malafaia (líder da Assembleia de Deus Vitória em Cristo promotora da Marcha para Jesus da cidade do Rio de Janeiro) denomina seus adversários políticos: "esquerdopata", "petralha" e "feminazi"?

O pastor Silas talvez seja a liderança religiosa mais pródiga em oferecer exemplos para o que estamos tratando neste artigo: em 30 de outubro de 2016, após a divulgação do resultado das eleições municipais da cidade do Rio de Janeiro, que dava a vitória ao bispo da IURD, Marcelo Crivella, o pastor Silas usou sua conta no Twitter e escreveu: "Cambada de esquerdopatas se ferraram, tomaram uma lavada histórica. Calados! (...)"; "Crivella venceu a intolerância, preconceito, manipulação jornalística, e o melhor, a esquerda comunista (...)"; "Chora Capeta! Chora Freixo!". Mais que um simples ato de hostilidade ou provocação, como noticiou a Folha de São Paulo, os comentários do pastor visavam mobilizar discursivamente tanto evangélicos quanto a parcela de seus seguidores não evangélicos, ao apelar para a macroidentidade cristã: "Parabéns Cristãos! Nunca mais esses esquerdopatas vão nos enganar (...)", ao mesmo tempo em que identifica um adversário tangível contra o qual lutar: "Ajudei a derrubar todos os candidatos do PSOL, PERDERAM TODAS! Perde o at gay [ativismo gay] para ajudar mais um pouco (...)".

Operando uma simplificação de uma realidade complexa, criando uma macroidentidade "nós" cristã-moral e, no mesmo turno, um "eles", vistos como demiurgos da desestabilização social, depositários das mazelas e medos que afligem boa parte da sociedade em momentos de convulsão social, neste caso, o "ativismo gay", o PSOL, os "petralhas", as "feminazis", ou simplesmente o mal, o "Capeta". Ainda é interessante observar como o discurso do pastor Silas Malafaia tem um duplo papel funcional, que, ao mesmo tempo que coloca o pastor em um lugar privilegiado na disputada pela arena religiosa brasileira, amplifica seu discurso para além da população evangélica.

Ao contrário de outros líderes do segmento evangélico pentecostal, que se concentram em soluções biográficas, como Edir Macedo, que dá ênfase a questões pecuniárias, ou a Waldemiro ${ }^{8}$, que se concentra na cura, Silas

\footnotetext{
${ }^{8}$ Waldemiro Santiago de Oliveira, o apóstolo Waldemiro, trata-se do fundador e principal líder da Igreja Mundial do Poder de Deus. O mesmo permaneceu vinculado à IURD durante 18 anos, onde exerceu a função de bispo (SANTOS, 2017, p.61).
} 
surge com um produto bastante requisitado nos dias atuais, principalmente em tempos de Lava Jato, patos da FIESP e passeatas verde-amarelas contra a corrupção: a moral! O discurso moral proferido por Malafaia e replicado por um sem número de outras lideranças evangélicas, como os também pastores e, neste caso, parlamentares, como o senador Magno Malta (PRES) e o deputado Marcos Feliciano (PODE-SP), apresenta-se como um forte amálgama capaz de conectar ansiedades e medos pessoais, tributários de um momento histórico marcado por fortes transformações, ao discurso moral de fundo religioso e a uma narrativa de longa duração. Porém, o mal não está longe, não vem de fora nem do estrangeiro, ao contrário, senta-se ao seu lado na escola, almoça com você no refeitório do trabalho, enfim, nos termos de Luhmann (2007), tal operação é capaz de transformar a indeterminação gerada pelo contínuo processo de complexificação social em possibilidades determinadas e determináveis, produzindo interpretações do mundo através de generalizações simbólicas.

Como mostramos alhures (GRACINO JUNIOR, 2016), no caso brasileiro, as instituições religiosas que têm logrado maior êxito em termos numéricos são as que se concentram nas preocupações com os medos sociais diários: nos empregos de uma montadora no Brasil que podem ser ceifados em uma reunião da diretoria de multinacional em Wolfsburg ou Shanghai; nas crises financeiras, que, sem aviso prévio e sazonalmente, levam países à miséria e empresas à bancarrota; na violência vivida e/ ou transmitida cotidianamente pelos meios de comunicação, ou nas diversas fantasmagorias que parecem ameaçar o núcleo familiar. Nesse cenário, o discurso das opções religiosas liberais, com sua eterna mensagem sobre a universalidade humana, que conectam problemas locais a estruturas complexas e pouco tangíveis, como capitalismo, mercado financeiro, problemas ambientais globais, só aguçam o sentimento de desamparo e de ansiedade; ao contrário, a opção conservadora lhes ensina a ir em frente, oferece-lhes um mapa da salvação diante dos desafios que se renovam a cada dia. Vejamos a esse respeito a entrevista do arcebispo do Rio de Janeiro, Dom Orani Tempesta:

Vamos ter fóruns sobre o jovem no mundo, debate com a ONU sobre o futuro da humanidade, direitos humanos, diálogo interreligioso e ecumênico, estímulo à sustentabilidade e acessibilidade, a questão dos dependentes químicos. O importante é que esses debates levem depois a consequências ao mundo inteiro, já que teremos jovens de mais de 175 nações reunidos. A Jornada vem justamente dizer ao jovem que tenha esperança. Que os jovens 
tenham na igreja a sua parceira. Coragem, nós acreditamos em vocês. Temos certeza que vai valer a pena confiar na juventude, eles sabem trabalhar e fazer as coisas irem para frente ${ }^{9}$. [Grifos nossos)].

Já Silas Malafaia, em entrevista concedida à $\mathrm{BBC}$, a respeito do que chamou "Ato profético pelo fim da corrupção e da crise econômica no Brasil", segundo o pastor, "O ato profético é para declarar que a corrupção vai acabar, que toda a bandalheira vai ser exposta". Ao ser indagado pelo jornalista sobre a complexidade da promessa, Malafaia argumenta: "Quando Israel vivia períodos de crise, levantava um profeta que dizia que viriam tempos de paz e prosperidade. E aquilo tudo mudava. Então nós conhecemos esta prática". Outro líder religioso, Estevam Hernandes, bispo da Igreja Renascer em Cristo e idealizador da Marcha para Jesus na cidade de São Paulo, abriu a edição de 2017 do evento com a oração: "Pai, tira a fome e a corrupção. O Deus de paz vai esganar (sic) o satanás sob os teus pés (...)" e continua: "É por isso esse clamor, por isso oramos para que a corrupção tenha um fim. Ela [corrupção] destrói o ser humano, tira suas expectativas e seus sonhos". No mesmo evento, declara: "A oração inicial foi para mostrar que só ela mesmo, a oração, para quebrar esse ciclo de corrupção que estamos enfrentando no país".

Antes de prosseguirmos, convém retomar nossa tese central neste artigo, qual seja, a de que o Estado brasileiro não tem conseguido obter sua autolegitimação de maneira autossuficiente, através de recursos cognitivos que não dependam de discursos estranhos à esfera política, com isso tem aberto espaço para discursos religiosos do tipo conservador. Neste sentido, é interessante notar que nossa interpretação do caso brasileiro é justamente uma das possibilidades aventadas por Habermas em seu Naturalismo e Religião, mas descartada para sociedades liberais abastadas. Habermas observa que uma modernização "descarrilhadora" da sociedade poderia esgarçar, em sua totalidade, o laço democrático e consumir o tipo de solidariedade da qual o Estado democrático depende, o que levaria à transformação de cidadão em mônadas individualizadas que agem guiadas

\footnotetext{
9 Disponível em: <http://g1.globo.com/jornada-mundial-da-juventude/2013/noticia/2013/06/ementrevista-ao-g1-dom-orani-fala-dos-preparativos-e-desafios-da-jmj.html>. Acesso em 10 de outubro de 2016.
} 
pelos próprios interesses e que acionam seu direito subjetivo como se fossem armas apontada para os outros. Em seu entendimento, "em sociedades onde impera uma economia mundial, e uma sociedade mundial, é possível detectar evidências de um esmigalhamento da solidariedade de cidadão do Estado" (HABERMAS, 2007, p.121). Para o autor, em tese que se aproxima às de Taylor $(1994,2011)$ e Sennett (1999), os mercados, que não podem ser democratizados da mesma maneira que administraçoes estatais, assumem cada vez mais funções de controle e domínio da vida, que até então tinham sido mantidas de forma normativa por tipos de comunicação política ou prépolítica. Tal processo inverte a polaridade das esferas privadas, transpondo o agir orientado pelo sucesso e por preferências próprias, fazendo encolher, por conseguinte, os domínios que dependem de pressões de legitimação pública, fortalecendo a privatização das agências de cidadão do Estado (HABERMAS, 2007, p.122).

Neste sentido, acreditamos que o processo de redemocratização do país levado a cabo após a Constituição de 1988 não chegou a constituir uma arena pública dialogal, antes, assistimos ao fatiamento das instituições do Estado entre os conglomerados financeiros que, por sua natureza, são não democráticos. Desta forma, o que assistimos desde o agudo processo de privatização dos governos Collor e FHC, com refluxos em áreas específicas nos governos do Partido dos Trabalhadores, foi a inclusão de diversos setores da sociedade brasileira em uma espécie de "cidadania pelo consumo". Parte de setores importantes para o acesso a uma cidadania plena, como saúde, educação e transporte, foram entregues à iniciativa privada e dependiam do interesse pecuniário desta para seu desenvolvimento pleno. Não foi sem motivo que as manifestações de junho de 2013 tiveram como estopim o aumento do custo do transporte público.

Assistimos a um cenário em que a cultura política brasileira é premida de um lado pelos interesses privados, que impõem uma espécie de "teto" ao acesso à cidadania, e desgastada de outro por um discurso midiático que imputou ao ocupante do Estado - no caso o PT - o papel de único artífice das contradições e limites do arranjo mercado-cidadania, potencializando e até precipitando o esgarçamento completo das instâncias democráticas. Nesse ínterim, assistimos à ascensão de diversos discursos, estranhos à arena política, que mobilizam os cidadãos para ações coletivas que se articulam a partir de interesses estritamente privados, projetando-se no espaço público e dificultando a realização de interesses civis mais universais.

Antes de prosseguirmos, é interessante notar que se trata de jovens que 
tomaram consciência de sua trajetória individual e como atores políticos durante o desenrolar dos governos do Partido dos Trabalhadores. Neste sentido, rebelar-se contra as políticas públicas em curso nesse período faz parte da cultura juvenil, ainda que, como veremos, a variável religião mostrase mais relevante diante da variável etária. São os jovens participantes da Marcha para Jesus portadores de opiniões públicas mais conservadoras diante dos jovens dos outros segmentos religiosos, tanto por sua extração de classe quanto por sua filiação religiosa. Tal evidência justifica não termos tomado a categoria juventude como uma categoria definidora da opinião pública, principalmente, na categoria religião.

Neste sentido, quando perguntados sobre o grau de confiança no Governo Federal ou na Política (Gráficos 1 e 2), vemos uma gradação na variação que vai dos índices mais positivos dos Católicos da JMJ, em que 32,1 e $22,2 \%$, respectivamente, dizem "confiar de alguma forma", enquanto evangélicos da Marcha ficam com 16,8 e 10,3\%, já os participantes da caminhada batem os 19,4 e 15,2\%, do outro lado, os católicos são também os que menos desconfiam, ficando os evangélicos e os participantes da Caminhada com índices que rodam os $65 \%$ de desconfiança no Governo e $70 \%$ na política, de modo geral.

\section{Gráfico 1}

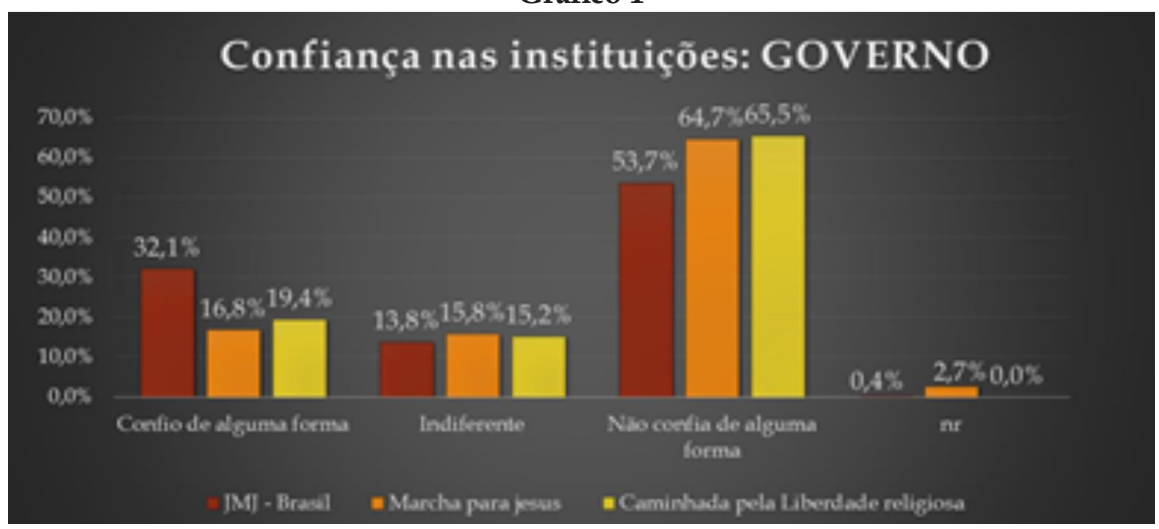

Fonte: Mariz, Cecília e Gracino Junior. As novas configurações da Religião 


\section{Gráfico 2}

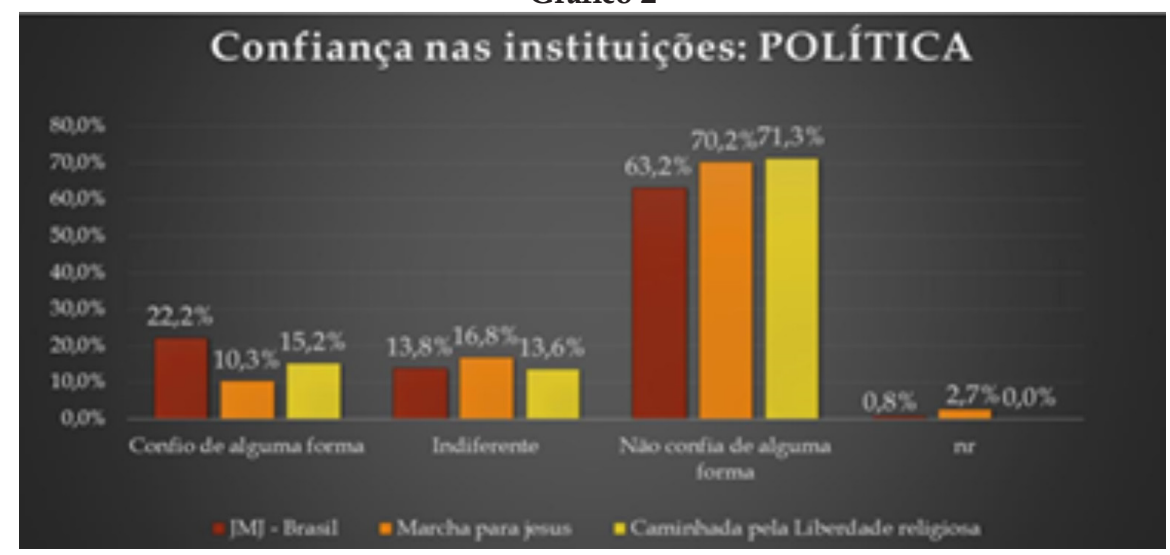

Fonte: Mariz, Cecília e Gracino Junior. As novas configurações da Religião

Tal cenário parece ser tributário tanto dos fatores elencados quanto da evolução diacrônica da crise política do país, que tende a ser mais percebida entre os participantes da Caminhada por Liberdades Laicas, cujo levantamento foi realizado em 2016, ao passo que os anteriores se deram em 2013, no caso das Jornadas, e em 2015, Marcha. Neste mesmo sentido, quando comparados a outras pesquisas, os altos indicies de confiança nas instituições religiosas, em detrimento das demais instituições, são corroborados pela pesquisa realizada pelo IBOPE $(2013)^{10}$ - em paralelo a esta pesquisa -, no qual as instituições religiosas inspiram mais confiança, com $66 \%$ dos entrevistados, perdendo apenas para os bombeiros (77\%), enquanto o Congresso Nacional teve $29 \%$ e os partidos políticos $25 \%$, sendo estes os últimos da lista. A pesquisa realizada por Solano, Ortellado e Moretto (2017) ${ }^{11}$ mostra também essa tendência, além de indicar uma desvinculação entre a pertença evangélica e o voto, ou seja, revela que a equação "irmão vota em irmão" que indicava uma transferência de votos quase que automática entre segmentos evangélicos e seus candidatos (FERNANDES et al., 1998) pode estar defasada.

\footnotetext{
10 Disponível em: <http://www.ibope.com.br/pt-br/noticias/paginas/cai-a-confianca-dos-brasileirosnas-instituicoes-.aspx>. Acesso em 30 de janeiro de 2018.

11 Disponível em: <https://brasil.elpais.com/brasil/2017/06/16/politica/1497624155_222166.html>. Acesso em 12 de fevereiro de 2018.
} 
No caso de nosso levantamento e das pesquisas qualitativas complementares, ainda que não se tenha aferido a intenção de voto, podemos apontar dois pontos: o primeiro é que há um descompasso entre a opinião pessoal e a opinião pública dos fiéis, principalmente entre o grupo evangélico. Embora discordem privadamente das lideranças em diversos temas, como ficou nítido em algumas entrevistas qualitativas e em grupos focais, os evangélicos tendem a seguir a orientação da igreja quanto ao voto, principalmente em se tratando de eleições para cargos proporcionais. Em segundo, mostra que inquéritos realizados em anos não eleitorais tendem a falsear as respostas dado o baixo engajamento político dos entrevistados. É interessante notar que os dois fenômenos citados têm a mesma identidade e lastro social, a corrosão da cultura política no país, que leva a um fraco engajamento entre esfera subjetiva e política, que acaba por facilitar o trabalho das lideranças religiosas na captura desse voto. Neste caso, é bom lembrar que a população religiosa difere muito pouco da média da população brasileira.

A discrepância entre posição pessoal e opinião pública fica mais aguda quando olhamos os Gráficos 3 e 4, a seguir:

Gráfico 3

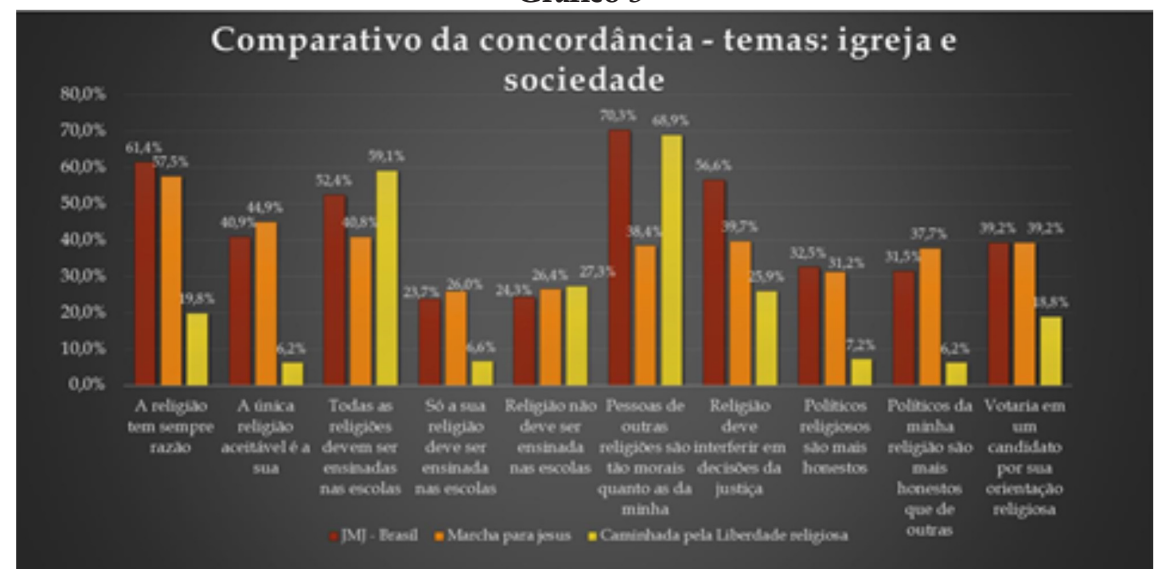

Fonte: As novas configurações da religião 


\section{Gráfico 4}

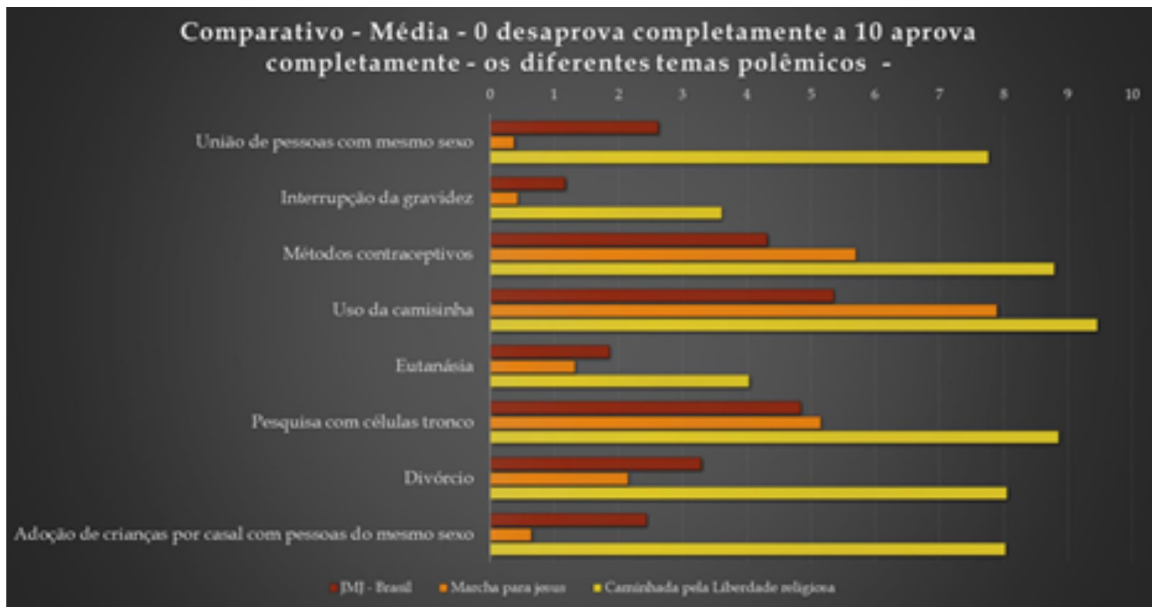

Fonte: As novas configurações da religião

No que tange à opinião registrada a respeito de temas polêmicos, os dados dos survey's demonstram que os jovens participantes da Marcha para Jesus, quando comparados aos jovens participantes da Caminha e da Jornada, expõem maior desaprovação em relação à união de pessoas do mesmo sexo, interrupção da gravidez, eutanásia, divórcio e adoção de crianças por casal formado por pessoas do mesmo sexo. Por outro lado, em consonância com a posição da Igreja Católica, os jovens encontrados na Jornada manifestaram maior desacordo acerca do uso de métodos contraceptivos, uso de camisinha e pesquisa com células-tronco. Tal postura registrada diante de temas polêmicos revela algumas nuances que diferenciam os dois grupos citados. Nota-se que entre os evangélicos as questões que provocam maior desacordo estão relacionadas ao discurso bastante veiculado por lideranças evangélicas, em que a defesa da família tradicional (a qual é entendida, no discurso evangélico, como um núcleo familiar formado por casal heterossexual e seu(s) filho(s)) é enfatizada. Já entre os católicos percebe-se que a maior discordância se concentra nas questões diretamente ligadas ao debate sobre responsabilidade reprodutiva. Ao mesmo tempo, tanto católicos quanto evangélicos demonstram grande desacordo em relação a temas polêmicos que envolvem questões relacionadas ao debate sobre a inviolabilidade da vida humana.

Como dissemos, ainda que desaprovem publicamente os temas em contraste com a opinião pública e preceitos de sua denominação religiosa, 
trabalhos qualitativos realizados com grupos de jovens religiosos mostraram que a posição pessoal, inclusive no que tange ao que chamamos de "temas polêmicos", é discrepante. Em grupo focal realizado na Assembleia de Deus Vitória em Cristo no bairro de Campo Grande, por exemplo, os jovens relataram a convivência, tolerância e acolhida de membros homossexuais da igreja, indicando certo desacordo com relação à posição pública da liderança dessa igreja. No entanto, ainda que divirjam da posição majoritária da liderança em nível pessoal e nas relações interpessoais, observamos que os jovens apoiam as tomadas de decisão públicas dessas lideranças, o que pode indicar a não conexão de atos individuais com narrativas mais amplas e complexas.

A presença da "pauta moral" também aparece quando se observa a postura empregada no voto e as conviçcões políticas acerca de determinados assuntos. Deste modo, os dados da pesquisa apontam que, entre os entrevistados, 31,5\% dos católicos e 37,7\% dos evangélicos acreditam que os políticos de suas respectivas religiões são mais honestos do que de outras. Igualmente, $39,2 \%$ dos jovens do primeiro grupo e 39,2\% do segundo afirmaram que votariam em um candidato por sua orientação religiosa. Do lado oposto, apenas 6,2\% dos jovens entrevistados na Caminhada disseram acreditar que os políticos seguidores da mesma religião que o entrevistado são mais honestos, enquanto 18,8 \% responderam positivamente à afirmativa de que votariam em um candidato por sua orientação religiosa.

\section{Considerações Finais}

Em resumo, a análise dos dados da pesquisa demonstrou, através do mapeamento da influência das instituições religiosas na opinião pública de seus fiéis, que o grupo evangélico, quando comparado aos católicos e aos jovens participantes da Caminhada, é o que apresenta maior discrepância entre sua opinião pública e os "temas controversos", menor tolerância à diversidade religiosa, maior desconfiança com relação às instituições públicas e maior confiança na instituição religiosa. Conjuntamente, a "pauta moral" adotada pelas instituições religiosas também se mostra bastante premente como influenciadora do voto e inspiradora das convicções políticas assumidas pelos grupos católico e evangélico. Da mesma forma, a "pauta moral" defendida pelas instituições religiosas interfere diretamente nos níveis de tolerância empregados nas questões relativas à diversidade religiosa e de gênero. Assim sendo, com o baixo nível de confiança 
depositados nas instituições públicas, portadoras de pautas mais universais, pode-se dizer que tal conjuntura indica uma perspectiva moralizadora do espaço público marcadamente influenciada pelos preceitos defendidos pela instituição religiosa.

\section{Referências}

BABBIE, Earl.

(1999). Métodos de Pesquisas de Survey. Belo Horizonte, Ed. UFMG.

BEYER, Peter.

(1990). A privatização e a influência pública da religião na sociedade global. In: FEATHERSTONE, Mike (Org.). Cultura global: nacionalismo, globalização e modernidade. Petrópolis, Vozes. p. 395-419.

BICKMAN, Leonard; ROG, Debra (Eds.). (2008). The SAGE handbook of applied social research methods. 2 ed. Newbury Park, Sage.

BRAGA, Ruy.

(2012). A política do precariado: do populismo à hegemonia lulista. São Paulo, Boitempo.

BURDICK, John.

(1998 [1993]). Procurando Deus no Brasil: a igreja católica progressista no Brasil na arena das religiões urbanas brasileiras. Rio de Janeiro, Mauad.

FERNANDES, Rubem C.; SANCHIS, Pierre; VELH0, Otávio G.; PIQUET, Leandro; MARIZ, Cecília; MAFRA, Clara.

(1998). Novo nascimento: os evangélicos em casa, na política e na igreja. Rio de Janeiro, Mauad.

FOUCAULT, Michel.

(1979). Microfísica do poder. Rio de Janeiro, Edições Graal.

FREITAS, Henrique et al.

(2000). 0 método de pesquisa survey. Revista de Administração da USP, v. 35, n. 3, p.105112, jul./set. São Paulo.
GIUMBELLI, Emerson.

(2008). A presença do religioso no espaço público: modalidades no Brasil. Religião \& Sociedade, v. 28, n. 2, p.80-101. Rio de Janeiro.

GRACINO JUNIOR, Paulo.

(2016). A demanda por deuses: globalização, fluxos religiosos e culturas locais nos dois lados do Atlântico. Rio de Janeiro, Eduerj.

(2010). À sombra das catedrais: religião e hierarquia social em uma cidade do interior mineiro. Teoria \& Sociedade (UFMG), v. 10, p. 21-46.

(2008) Surtos de aconselhamento e soluções biográficas? a Igreja Universal e a nova face do fenômeno religioso na sociedade contemporânea. Revista Anthropológicas, v. 1, p. 32-54.

IANNACCONE, Laurence R.

(1994). Why Strict Churches Are Strong. American Journal of Sociology, v. 99, n. 5, p.1180-1211.

HABERMAS, Jürgen.

(2007). Entre naturalismo e religião. Rio de Janeiro, Tempo Brasileiro.

(2003). Mudança estrutural da esfera pública: investigações quanto a uma categoria da sociedade burguesa. Rio de Janeiro, Tempo Brasileiro.

(2001). 0 discurso filosófico da modernidade. São Paulo, Martins Fontes.

(1989). Consciência Moral e Agir Comunicativo. Rio de Janeiro, Tempo Brasileiro. 
HERVIEU-LÉGER, Danièle.

(2005). 0 Peregrino e o Convertido: a religião em movimento. Lisboa, Gradiva.

(1997). Representam os surtos emocionais contemporâneos o fim da secularização ou o religião?. Religião \& Sociedade, v.18, n.1, p. 31-48. Rio de Janeiro.

HONNETH, Axel.

(2009). Luta por Reconhecimento: a gramática moral dos conflitos sociais. 2. ed. São Paulo, Editora 34.

KELLEY, Dean M.

(1978). Why Conservative Churches Are Still Growing. Journal for the Scientific Study of Religion, v.17, n.2, p.165-72.

MACHAD0, Maria das Dores Campos Machado; BURITY, Joanildo.

(2014) A ascensão política dos pentecostais na avaliação de líderes religiosos. Dados, v. 57, p. 601-629. Rio de Janeiro.

MARIANO, Ricardo.

(2011). Laicidade à brasileira: Católicos, pentecostais e laicos em disputa na esfera pública. Civitas, v.11, n.2, p. 238-258.

MARIZ, Cecília.

(1994). Coping With Poverty: Pentecostals And Base Communities In Brazil. Philadelphia, Temple University Press.

MARIZ, Cecília; GRACINO JUNIOR, Paulo.

(2013). As Igrejas Pentecostais no censo de 2010. In: MENEZES, Renata; TEIXEIRA, Faustino. (Org.). Religiões em movimento: 0 censo de 2010. Petrópolis, Vozes. p. 161-174.

MENESES, Jonatas Silva.

(2017). Igreja Universal do Reino de Deus (IURD): institucionalização e mudanças de paradigmas. Revista Lusófona de Ciência das Religiões, v. 1, p. 423-436.

LUHMANN, Niklas.

(2009). Introdução à Teoria dos Sistemas.

Petrópolis, Vozes.
(2007). La religión de la sociedade. Madri, Trotta.

(1996). Confianza. México, Editorial Anthropos.

OFFE, Claus.

(1999). How Can We Trust Our Fellow Citizens? In: WARREN, M.E. (Ed). Democracy and Trust. Cambridge, Cambridge University Press.

OLIVEIRA, Isabel de Assis Ribeiro de.

(2006). 0 mal-estar contemporâneo na perspectiva de Charles Taylor. Revista Brasileira de Ciências Sociais, 21(60), p.135145.

PIERUCCI, Antônio Flávio.

(1989). Representantes de Deus em Brasília: a bancada evangélica na Constituinte. Ciências Sociais Hoje, ANPOCS, p. 104-132.

PORTIER, Phelippe.

(2011). A regulação estatal da crença nos países da Europa Ocidental. Religião e Sociedade, v. 31, n.2, p. 11-28.

SANTOS, Clécio Jamilson Bezerra.

(2017). "A gente tem que se humilhar": a atuação da Igreja Mundial do Poder de Deus em Juazeiro do Norte. Tese de mestrado apresentada ao Programa de Pós-Graduação em Ciências Sociais da Universidade Federal do Rio Grande do Norte.

SENNETT, Richard.

(2006). A corrosão do caráter: consequências pessoais do trabalho no novo capitalismo. São Paulo, Record.

(1999). O Declínio do Homem Público: as tiranias da intimidade. São Paulo, Companhia das Letras.

SINGER, André et al.

(2016). As contradições do lulismo: a que ponto chegamos?. São Paulo, Boitempo.

SINGER, André et al.

(2012). Os sentidos do lulismo. Reforma gradual e pacto conservador. São Paulo, Companhia das Letras. 
SMITH, Christian S. (0rg.).

(2003). The secular revolution: power, interests, and conflict in the secularization of American public life. Berkeley, University of California Press.

(1998) American evangelicalism: embattled and thriving. Chicago, The University of Chicago Press.

SOLANO, Esther; ORTELLAD0, Pablo; MORETT0, Márcio.

(2017). Guerras culturais e populismo antipetista. Em Debate, v. 8, p. 35-45.

STARK, Rodney; FINKE, Roger.

(2000). Acts of Faith: Explaining the Human Side of Religion. Berkeley, University of California Press.
TAYLOR, Charles.

(2011). A ética da autenticidade. São Paulo, É Realizações.

(1994). As Fontes do Self - A Construção da Identidade Moderna. São Paulo, Edições Loyola.

\section{Recebido em}

abril de 2018

Aprovado em

novembro de 2018 